\title{
Side-loop method easily enables dual traction during gastric endoscopic submucosal dissection
}

The clip-with-line traction method is widely used in gastric endoscopic submucosal dissection (ESD), making ESD safe and speedy [1-3]. However, traction sometimes is only partially applied, and therefore, a sufficient effect may not be obtained. We devised a modified clipwith-line method called the side-loop method to apply traction simultaneously to two points using one line, which results in sufficient traction over a wider area.

Dental floss is the only thing needed to create a side-loop ( $\mathbf{F i g} \mathbf{1 a}$ ). After the circumferential mucosal incision is performed, the endoscope is removed from the patient. The dental floss with sideloop is connected to a hemoclip (EZ clip, HX-610-135S; Olympus, Tokyo, Japan), and the endoscope is reinserted ( $\triangleright$ Fig. 1b). As with the conventional clip-withline method, the hemoclip is placed at the edge of the lesion ( $\mathbf{F i g . 2 a}$ ). The side-loop is then hooked using another clip and placed at another edge of the lesion, thus allowing dual traction, and traction over a wider area ( $\mathbf{F i g . 2 b}$ ) [4]. During a medical check-up, a 72-year-old man underwent endoscopy, which revealed a $23-\mathrm{mm}$ type 0 -Ilc early gastric cancer located on the greater curvature of the middle stomach body. ESD was performed with a GIF-H290Z endoscope and 2.0-mm DualKnife J (Olympus) ( $\triangleright \mathbf{V i -}$ deo1). After circumferential marking was done and a mucosal incision was made, the side-loop method was used to obtain dual points of traction. Traction could be applied over a wide area, thus allowing the submucosal dissection to proceed easily. The lesion was resected en bloc within 33 minutes. The pathological result was moderately differentiated tubular adenocarcinoma, depth of submucosal invasion $300 \mu \mathrm{m}$, negative lymphovascular invasion, and negative margin.

In conclusion, the side-loop method easily, efficiently, and inexpensively enables
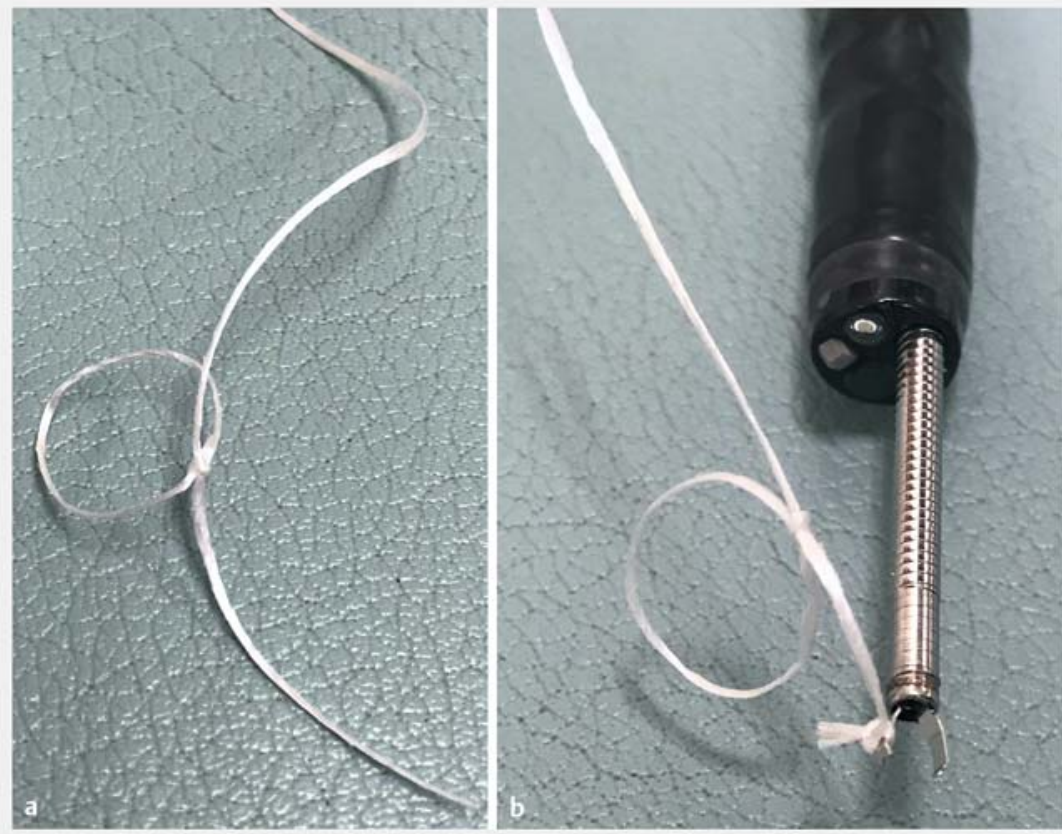

Fig. 1 a A side-loop was formed with dental floss in advance of the procedure. The sideloop was easily created by tying dental floss around a $2.5-\mathrm{mL}$ syringe. $\mathbf{b}$ The dental floss with side-loop was attached to the hemoclip.
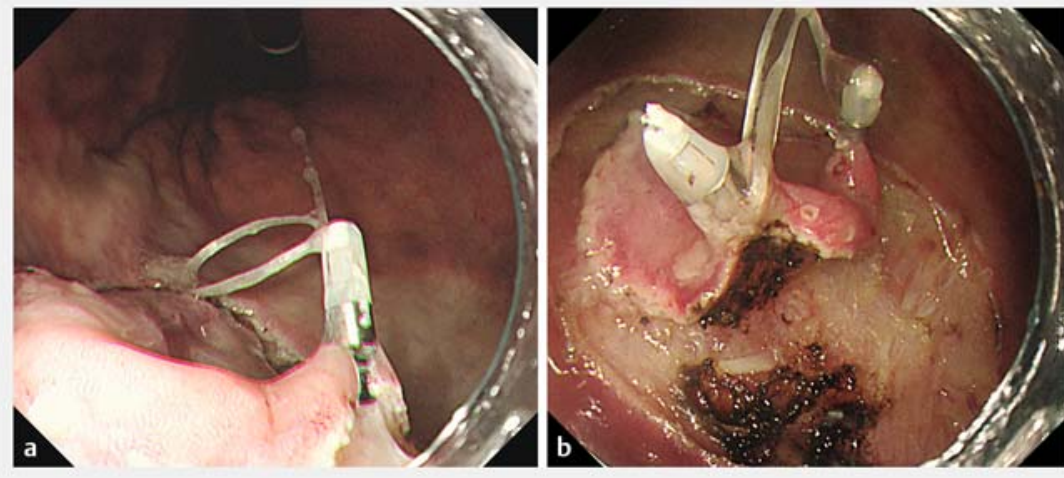

- Fig. 2 a ESD was performed with a VIO 300 D electrosurgical unit (Erbe Elektromedizin, Tübingen, Germany) using the following settings: Endo Cut Q, effect 2, duration 3, interval 2; swift coagulation, effect 4, $50 \mathrm{~W}$; forced coagulation, effect 3, $20 \mathrm{~W}$. After the circumferential mucosal incision was made, a hemoclip with the side-loop of dental floss tied to it was placed at the edge of the lesion. $\mathbf{b}$ The side-loop was hooked with another clip and placed on another edge of the lesion. Dual traction thus could be applied over a wide area.

dual traction, which permits easier per-

formance of gastric ESD. 


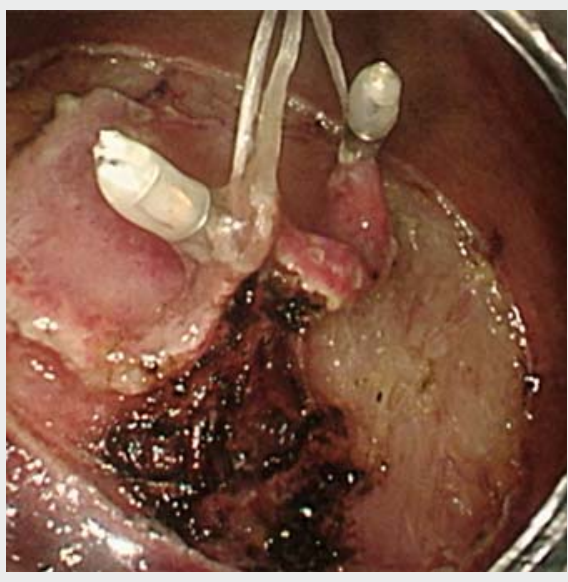

Video 1 Side-loop method for dual traction during gastric endoscopic submucosal dissection.

\section{Competing interests}

The authors declare that they have no conflict of interest.

The authors

Sho Sasaki', Jun Nishikawa², Kazuhiro Yamamoto ${ }^{1}$, Isao Sakaida ${ }^{3}$

1 Department of Gastroenterology, Saiseikai Yamaguchi Hospital, Yamaguchi, Japan

2 Faculty of Laboratory Science, Yamaguchi University Graduate School of Medicine, Yamaguchi, Japan

3 Department of Gastroenterology and Hepatology, Yamaguchi University Graduate School of Medicine, Yamaguchi, Japan

Corresponding author

Sho Sasaki, MD, PhD

Department of Gastroenterology, Saiseikai Yamaguchi Hospital, Midorimachi 2-11,

Yamaguchi, 753-8517, Japan

Fax: +81-083-901-6111

sho.ssk.nv21@gmail.com

\section{References}

[1] Oyama T. Counter traction makes endoscopic submucosal dissection easier. Clin Endosc 2012; 45: 375-378

[2] Yoshida M, Takizawa K, Ono H et al. Efficacy of endoscopic submucosal dissection with dental floss clip traction for gastric epithelial neoplasia: a pilot study (with video). Surg Endosc 2016; 30: 3100-3106

[3] Suzuki S, Gotoda T, Kobayashi Y et al. Usefulness of a traction method using dental floss and a hemoclip for gastric endoscopic submucosal dissection: a propensity score matching analysis (with videos). Gastrointest Endosc 2016; 83: 337-345

[4] Fujita K, Takeshita M, Moriyama E et al. Novel technique for endoscopic submucosal dissection using an elastic thread delivery hood. Endoscopy 2020; 52: E178-E180

\section{Bibliography}

DOI http://dx.doi.org/10.1055/a-1236-3495

Endoscopy International Open 2020; 08: E1439E1440

Georg Thieme Verlag KG

Rüdigerstraße 14,

70469 Stuttgart, Germany

eISSN 2196-9736

(c) 2020. The Author(s).

This is an open access article published by Thieme under the terms of the Creative Commons Attribution-NonDerivative-NonCommercial License, permitting copying and reproduction so long as the original work is given appropriate credit. Contents may not be used for commecial purposes, or adapted, remixed, transformed or built upon. (https://creativecommons.org/licenses/by-nc-nd/4.0/) 